\title{
Creation and Operation Service of Education Knowledge Management Online Platform Based on IH5 Interactive Technology and Young Children Psychological Research under Large-Scale Epidemic Outbreak
}

\author{
Tiejun $\mathrm{Zhu}^{1 \text {, }^{*} \text {, Qingsong Sang }}{ }^{1}$ \\ ${ }^{1}$ Anhui Normal University, Wuhu, Anhui, China \\ ${ }^{2}$ Anhui Polytechnic University, Wuhu, Anhui, China \\ *Corresponding Author.
}

\begin{abstract}
:
In China, due to the influence of traditional concepts and realistic competitive environment, the preschool education has always been concerned and valued by the society and families. However, the current preschool education often focuses on the acquisition of knowledge and abilities, lack of in-depth consideration based on young children's behavior psychological analysis. In addition, the preschool education market is mixed, the preschool education knowledge development is uneven, the preschool education spreading path is traditional, combined with the impact of the epidemic, the demand for epidemic prevention and control promotes the booming of online education teaching and management platform. Based on the above background and the existence question, this paper uses the fashionable and interactive IH5 technology, in-depth study and analysis of young children's behavioral and psychological characteristics, and carries out resource integration, connectivity and mutual promotion in multiple dimensions such as young children, parents, kindergartens, the government, society and so on, to explorative create the young children education knowledge management platform and carry out operational service analysis and demonstration, with a view to providing solutions to the existing problems of China's preschool education, and to provide practical operation of service reference.
\end{abstract}

Keywords: IH5, Young children psychology, Preschool education, Online knowledge 


\section{BACKGROUND AND RELEVANT CONCEPTS}

\subsection{Background}

The enlightenment education in early childhood is related to the development of children in the future, their character and the formation of their life values. Due to the strong traditional concept of attaching importance to education, the large population leading to the strong competitiveness of the social reality, the long-term implementation of the family one-child policy in the early stage, and the current reduction of the birth rate (Table I), and so on, Chinese society and families attach great importance to preschool education. In the current positive social and economic environment, the preschool education market is booming. At the national level, a series of policy documents have been issued to promote, encourage and advocate preschool education. These include:

Table I. 2016-2020 changes in China's population growth rate and birth rate

\begin{tabular}{|l|l|l|l|}
\hline Year & $\begin{array}{l}\text { Population (Unit: Ten } \\
\text { Thousand People) }\end{array}$ & $\begin{array}{l}\text { Birth Population (Unit: Ten } \\
\text { Thousand People) }\end{array}$ & The Birth Rate (\%) \\
\hline 2016 & 138271 & 1786 & 12.95 \\
\hline 2017 & 139008 & 1723 & 12.43 \\
\hline 2018 & 139538 & 1523 & 10.94 \\
\hline 2019 & 140005 & 1465 & 10.48 \\
\hline 2020 & 141178 & 1200 & 8.5 \\
\hline
\end{tabular}

\subsubsection{Macro-policy aspect}

On November 15, 2018, the Opinions on deepening the reform and standardizing the development of pre-school education was issued, this document made directional adjustments and norms for the entire preschool education sector; On May 5, 2019, the China's Ministry of Education issued the Notice on the launch of the National Education Publicity Month Activity 2019. It is required to thoroughly implement the Guidelines for kindergarten education and the Guidelines for the learning and development of children aged 3-6, so as to prepare children for their future school life and lay a good quality foundation for their lifelong development; On May 9, 2019, the State Council issued the Guiding opinions on promoting the development of care services for young children under the age of three. By 2020, a system of policies, 
regulations, standards and norms for care services for young children and young children will have been preliminarily established, and a number of young children care service institutions with demonstration effect will be set up. By 2025, the system of policies, regulations, standards and norms for young children care services will be basically formed.

\subsubsection{Kindergarten construction aspect}

Encourage and support the construction of privately-run kindergartens, such as the 2017 Opinions of the State Council on encouraging social forces to establish education and promoting the healthy development of privately-run education" requirements: It will explore the cooperation of multiple subjects in running schools, promote the PPP model between government and social capital, encourage social capital to participate in the construction and operation of preschool education infrastructure, and provide professional services; To ensure the smooth establishment of inclusive kindergartens in rural areas, on February 23,2019, the China modernization of education 2035 was released, this document aims to establish a modern education system that serves lifelong learning for all by 2035 , including quality preschool education. Focusing on rural areas to improve the level of preschool education popularization, the document calls for the establishment of a more perfect preschool education management system, kindergarten management system and investment system, the vigorous development of public kindergarten, and the acceleration of the development of inclusive private kindergarten; On February 26, the China's Ministry of Education and other five departments also issued a new document, The management of supporting kindergartens in urban areas should be carried out by both the public and the private. This document aims not only to vigorously develop public kindergartens, but also to encourage and support more private kindergartens to provide inclusive services; These published policies are obviously biased towards the construction and development of inclusive kindergartens in rural areas, which is not only an emphasis on rural kindergartens, but also on preschool education in the country as a whole. These policies and measures undoubtedly provide a safe platform for children's learning and a guarantee for the construction of private kindergartens; On 11 June 2019, the China's Ministry of Education issued the Measures for the supervision of kindergartens, the Educational Supervision Department shall provide responsible supervision for kindergartens (including private kindergartens) within the administrative area and carry out regular supervision.

1.1.3 Management of preschool education institutions and teachers aspect

On February 23,2019, CPC Central Committee and the State Council issued the Implementation plan for accelerating the modernization of education to promote universal and 
inclusive development of preschool education, improve the management of preschool education and professional management team, strengthen the quality of kindergarten supervision and operational guidance; On the management of kindergarten teachers, suggestions have been put forward to improve the moral level of teachers in private and public kindergartens, for example, on November 16,2018, the China's Ministry of Education has published the Measures for the treatment of teachers' violation of professional ethics in kindergartens, which lists 11 types of acts against teachers' professional ethics that should be punished, targeting public and private kindergarten teachers.

\subsection{Relevant Concept}

\subsubsection{Definition of young children}

Encyclopedic dictionary for the definition of young children is: one-year-old children to six-years-old children. They can be divided into:

From one to three years of age, that is, "nursery period." This period of children speak from words to sentence, action from unstable to walk, can walk, can run. This period should pay attention to nutrition, more outdoor activities, prevent infectious diseases, prevent accidents, develop health habits, etc.

From four to six years of age, that is, "kindergarten period". In this period, children's limbs grow fast, their muscles gradually increase, they are active, and they are eager to learn and imitative. It is an important period of intellectual development. Attention should be paid to positive inspiration, to give more opportunities for group games and outdoor activities, in order to prepare for the future school education [1].

Therefore, the age range of young children involved in this paper is defined as 1-6 years old.

\subsubsection{IH5 interactive technology}

IH5 is a form of H5. However, compared to the previous H5 tools, the IH5 gives a higher level of functionality such as axis animation, motion simulation and monitoring, intelligent voice recognition, and late expandable tools, can maximize the realization of the user's desired function, to a certain extent, to provide users with unlimited imagination and strong technical support [2]. In the Internet age, based on the IH5 interactive technology to achieve a lot of platform applications, easy to operate, whether enterprises or individuals can design according 
to their own needs. The emergence of IH5 interactive technology also makes the design more simple and popular.

\subsection{Social Pain Points}

\subsubsection{Weak foundation of young childhood education}

Although the domestic young children education market develops vigorously in the surface, but the foundation is weak, no matter in the management mechanism or in the depth of teaching ideas, there is not a small gap with the foreign young children education market. In terms of systems and norms, in some developed countries there are strict norms for young children education schools and teachers. It is understood that foreign young children institutions, although the nature of young children institutions are different, however, the institution must be approved by the Education Department of the state or the local government authorized by the state government, and the quality of the educational program is certified by the folk preschool education association; The Australian Department of Education requires kindergarten teachers to have at least a three-level certificate in young children education, and all preschool education staff must have a work permit and first aid certificate to work with children.

\subsubsection{Young childhood education resource is uneven}

Young Children's mental development is not mature and their living range is relatively narrow. By psychological standards, most children will have some psychological problems. With the growth of age, children's mental development will gradually mature and form a fixed cognitive perspective and thinking mode. If there are still psychological problems in this period, it will have an impact on their future life [3]. At present, the young children education industry in China has many problems, such as low entry threshold, uneven level and quality of teachers, single curriculum, and poor teaching environment, lack of facilities in some countryside areas. Secondly, the main teaching content of preschool education pays more attention to the explanation of conceptual knowledge, whether it really has a positive guidance effect on young children is still unclear. Lack of market leading preschool education brand, there is a big gap with the advanced young children education brands in the world.

\subsubsection{Space limitation of children's activities}

On the one hand, with the rapid development of urbanization in China, the population of cities and towns is soaring, while most urban residents live in many-storied buildings, and the space of children's free activities is narrowing, it also makes it harder for kids to get in touch 
with other kids. On the other hand, parents attach great importance to their children. For safety reasons, their children's activities are restricted.

\subsubsection{Traditional and simple teaching methods}

The utilization rate of modern educational technology and equipment is low, the teaching method is simple and traditional, the classroom atmosphere is relatively dull and boring, children's learning enthusiasm cannot be stimulated. In addition, the concept of many teachers and schools only to take good care of children and no safety problems, therefore, children's active learning ability cannot be effectively developed, which hinders the development of children [4].

\subsubsection{Offline educational market is seriously hit by COVID-19}

Since 2020, the COVID-19 has had a huge impact on offline education and teaching, especially in the field of early childhood education. Because children's immune system is immature and vulnerable to disease infection, parents are very concerned about the healthy growth of children, so the offline early childhood education market almost stops.

Based on the above background and reasons, this paper uses the fashionable and interactive IH5 technology, in-depth study and analysis of young children's behavioral and psychological characteristics, and carries out resource integration, connectivity and mutual promotion in multiple dimensions such as young children, parents, kindergartens, the government, society and so on, to explorative create the young children education knowledge management online platform and carry out operational service analysis and demonstration, with a view to providing solutions to the existing problems of China's preschool education, and to provide practical operation of service reference.

\section{CREATION OF YOUNG CHILDREN EDUCATION KNOWLEDGE MANAGEMENT PLATFORM}

\subsection{Structural Framework (Figure 1)}




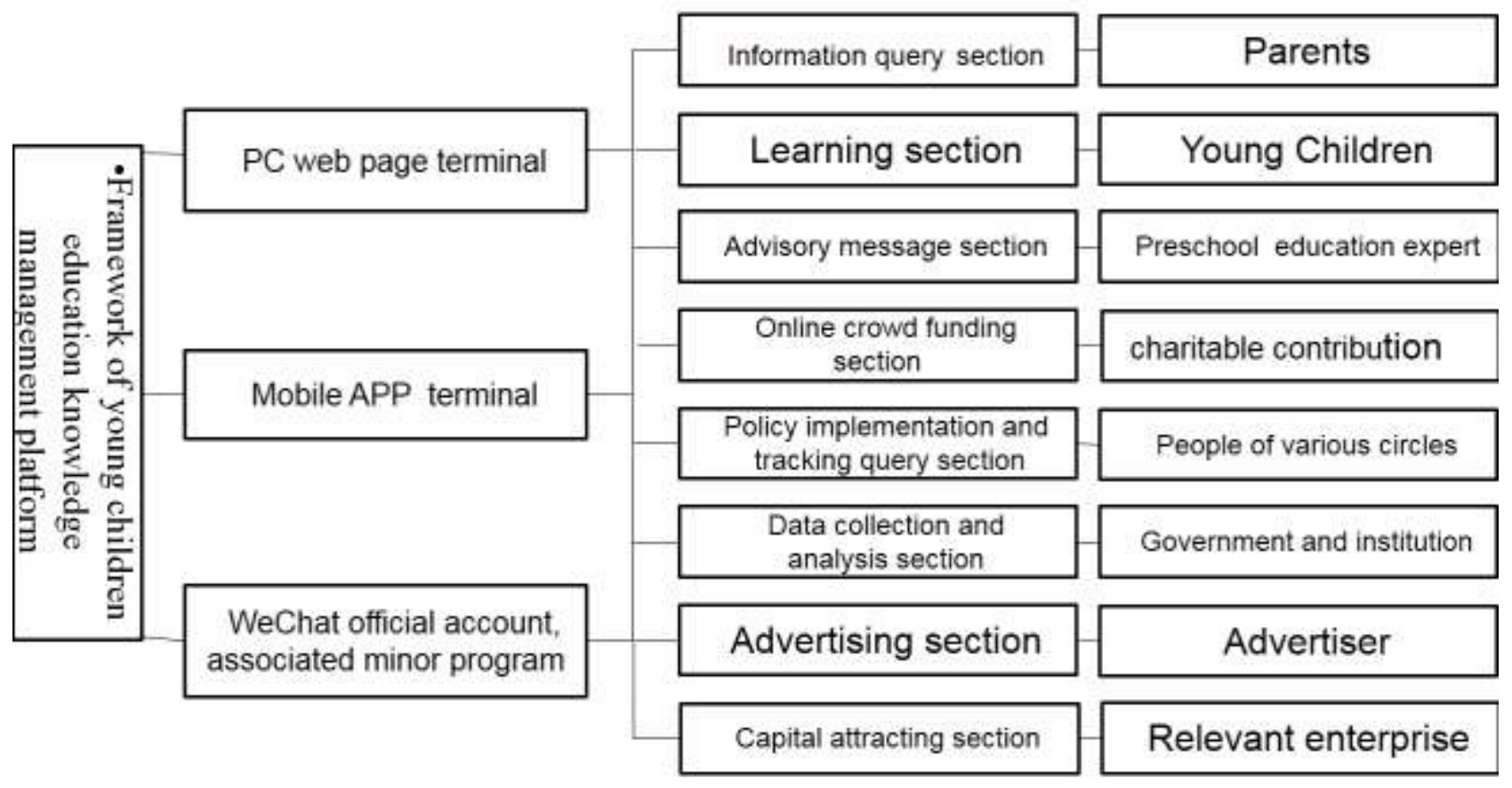

Fig 1. Framework of young children education knowledge management platform

\subsubsection{Information query section}

This section provides parents with information about preschool education knowledge and young children's growth. Relevant interface design is shown in Figure 2. 
Article History: Received: 10 May 2021 Revised: 20 June 2021 Accepted: 18 July 2021 Publication: 16 November 2021

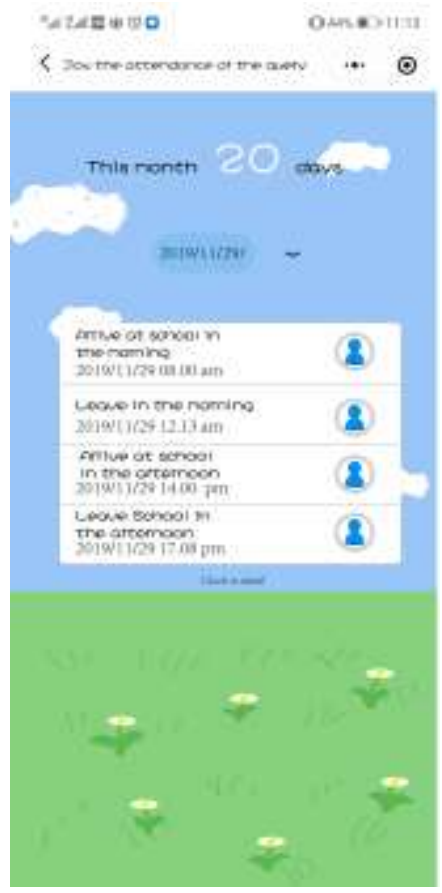

Fig 2. Interface design of information query section

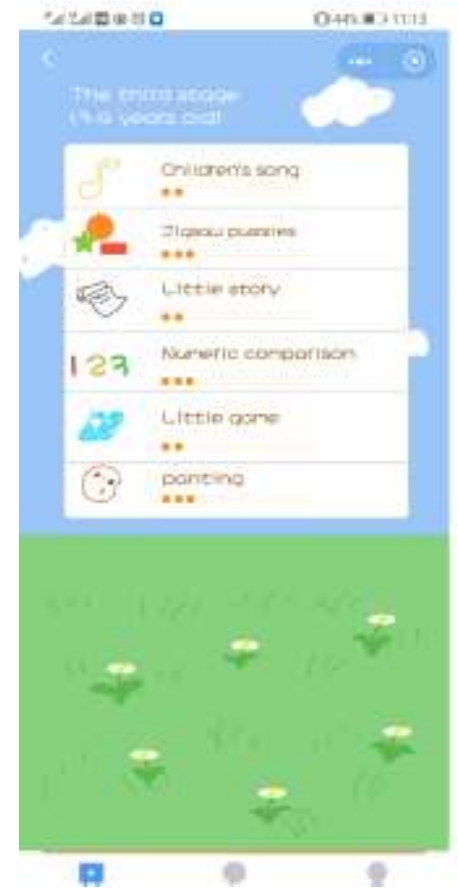

Fig 3. Interface design of learning section



Fig 4. Interface design of advisory message section

\subsubsection{Learning section}

This section provides rich text, books, videos, music, games, animations and other resources for young children to learn according to analysis of children's psychological and behavioral characteristics of different ages young children. Relevant interface design is shown in Figure 3.

\subsubsection{Advisory message section}

Introduce senior young children education experts to provide online Q \& A services in this section. Relevant interface design is shown in Figure 3.

\subsubsection{Online crowd funding section}

This section is aimed at children and families in need of help in difficulties, launching online charity support facing to the whole society, and so on. 


\subsubsection{Policy implementation and tracking query section}

On the one hand, this section is connected with the government departments to update the latest policy formulation and implementation in real time. On the other hand, this resource and data are provided to all sectors of the society for reference.

\subsubsection{Data collection and analysis section}

On the one hand, this section collects data and materials from government departments, kindergarten schools, domestic and foreign markets of preschool education, on the other hand, it conducts scientific analysis, sorting and induction to reveal the rules and development trends of young children education.

\subsubsection{Advertising section}

It not only publishes public service advertisements for publicity, but also uses a wide range of data resources and platform service customer group to attract advertisers to launch commercial advertisements, and the platform obtains advertising revenue.

\subsubsection{Capital attracting section}

While introducing enterprise cooperation investment (including risk investment) to provide operating funds for this education platform, it also uses platform channels to connect relevant enterprises with kindergartens in poverty areas and provide funds for running schools. In addition, through platform publicity, it sets up a positive social image for enterprises, so as to achieve a win-win situation.

\subsection{Research on Young Children's Psychological and Behavioral Characteristics}

\subsubsection{Young children's psychological and behavioral characteristics analysis model}

According to the existing research, it can set up a model to analyze the young children's psychological and behavioral characteristics, takes 3-year-old, 4-year-old and 5-year-old children groups ( 30 children in each group) as the test object, and sets the children's language score as the dependent variable and the age as the independent variable, to carry out the analysis of variance and test (ANOVA). The calculation formula of group individual variation is as follows: 


$$
\begin{aligned}
& S S_{R}=\sum k\left(\overline{X_{i}}-\bar{X}\right)^{2} \\
& =\sum \frac{\left(\sum X_{i}\right)^{2}}{k}-C \\
& d f_{R}=n-1 \\
& M S_{R}=\frac{S S_{R}}{n-1}
\end{aligned}
$$

The calculation formula of variation among groups is as follows:

$$
\begin{aligned}
& S S_{B}=\sum n_{j}\left(\overline{X_{j}}-\bar{X}\right)^{2} \\
& =\sum \frac{\left(\sum X_{j}\right)^{2}}{n_{j}}-C \\
& \mathrm{df}_{\mathrm{B}}=k-1 \\
& M S_{B}=\frac{S S}{k-1}
\end{aligned}
$$

It was found that the main effect of age was significant at the level of 0.001 . The score of 5year-old group was significantly higher than that of 3-year-old group $(\mathrm{P}=0.001)$ by Scheffe analysis of Post H0c Tests, and the difference of the rest was not significant at the level of 0.05 .

Using the score of false belief task as the dependent variable and age as the independent variable, the ANOVA test showed that the main effect of age was significant at the level of 0.001. The Scheffe analysis of Post H0c Tests showed that the three age groups were significantly different from each other at the level of 0.01 .

Using the score of social perception task as the dependent variable and age as the independent variable, the ANOVA test showed that the main effect of age was significant $(\mathrm{P}=0.18)$ at the level of 0.05 .

Linear regression analysis was conducted with the score of false belief task as the dependent variable, and language, age and gender as the independent variables. The results showed that $\mathrm{R}=0.620$. Among them, age and language can significantly predict the score of 
false belief task, the values were $0.702(\mathrm{P}<0.001)$ and $0.189(\mathrm{P}<0.01)$, respectively.

Linear regression analysis was conducted with the score of social perception task as the dependent variable and language, age and gender as the independent variables. The results showed that $\mathrm{R}=0.017$. Language, age and gender could not predict the score of social perception task significantly. It can be found that with the increase of age, social cognitive component is closely related to language ability, while the score of social perception task does not change significantly with age [5].

There are also studies that show that individuals in different cultures are influenced by language, living environment, social customs and other aspects, and have different understanding of the existence and function of psychological state [6].

\subsubsection{Psychological and behavioral characteristics in different stages}

\section{(1) 1-3 years old}

The age of 1-3 is the critical period for young children to learn to walk and speak. At 1-2 years of age, the movement of walking is slow but gradually stable, and the objects can be held accurately. In terms of language, before the age of 1.5, the language ability is not strong. They mainly say the objects they often touch, like to say reiterative words. At about three years old, the language is relatively fluent and can communicate with people normally. In terms of psychological activities, imagination began to sprout and thinking activities began to show. They will take chopsticks and dishes as their own instruments, start playing music activities, and start asking why he can do so? They start to become less cooperative, more independent and self-conscious.

\section{(2) 3-4 years old}

3-4 years old young children enter kindergarten, begin to closely contact the people outside the parents. Teachers and students appear in their life. The range of making friends began to be wide. Moreover, their knowledge depends on action, for example, textbooks and pictures describe birds flying, they may use body movements to show their understanding of "flying". This age group is also more likely to imitate, to see what other people are doing and to do what they are doing. Their emotions are also more influenced by other people. Maybe other children cry, and they cry too.

(3) 4-5 years old 
4-to 5-year-old children are more active, thinking more concretely, and can control themselves to follow the rules, but also understand some rules of the game, so while abiding by the rules, their ability to help each other and cooperate with each other has been constantly improved.

\section{(4) 5-6 years old}

5-6-year-old children are better at learning to ask questions. Abstract logical thinking begins to sprout. They are able to distinguish objects, find some rules among them, and have a relatively stable attitude and view on things.

\subsection{Young children education research and module implantation}

Bailey, a famous young children intelligence test expert, has found that the main factors influencing intelligence of children of different ages are different (Table II) [7]. With the increase of age, those complicated factors become more and more important. The main methods of intelligence training for young children of different ages are as follows: 10 months ago: visual tracking, social responsiveness, visual interest, movement flexibility etc.; 11-30 months: perceptual discover, vocal interaction, touching objects and language description, perceptual discrimination etc.; 31-50 months: understanding the relationship between objects, Memorizing object shape, verbal knowledge etc.; 51-70 months: complex spatial relationships, vocabulary etc. This also reminds us that according to the psychological characteristics of children of different ages, in different stages, the content of children's intelligence training should be emphasized in different aspect. In general, in early childhood, special attention should be paid to the cultivation of children's observation, attention and creativity [8].

\section{Table II. Importance ranking change table of main factors affecting intelligence of children of different ages}

\begin{tabular}{|l|l|l|l|l|l|l|l|l|l|l|}
\hline Age & $\begin{array}{l}\text { Physi } \\
\text { ology }\end{array}$ & $\begin{array}{l}\text { Matern } \\
\text { al love }\end{array}$ & $\begin{array}{l}\text { Perso } \\
\text { nal } \\
\text { safety }\end{array}$ & $\begin{array}{l}\text { Gam } \\
\mathrm{e}\end{array}$ & $\begin{array}{l}\text { Listeni } \\
\text { ng to } \\
\text { stories }\end{array}$ & $\begin{array}{l}\text { Learnin } \\
\text { knowle } \\
\text { dge }\end{array}$ & labor & $\begin{array}{l}\text { Strive } \\
\text { for } \\
\text { succes } \\
\text { s }\end{array}$ & $\begin{array}{l}\text { Trust } \\
\text { and } \\
\text { respe } \\
\text { ct }\end{array}$ & $\begin{array}{l}\text { Friends } \\
\text { hip }\end{array}$ \\
\hline 3 & 1 & 2 & 3 & 4 & 5 & & & & & \\
\hline 4 & 2 & 4 & 5 & 1 & 3 & & & & & \\
\hline 5 & 2 & & & 4 & & 1 & 3 & 5 & & \\
\hline 6 & 4 & & & & & 2 & 3 & & 1 & 5 \\
\hline
\end{tabular}




\subsubsection{Education module 1}

1-2-year-old children's enlightenment learning module. Children between 1 and 2 years of age are in the $n$ the stage of "perceptual movement". At this stage, children are still in the initial learning state and only rely on their movements to perceive and adapt to the environment. Therefore, many behaviors in this stage of children are born out of curiosity and exploration, rather than orderly psychological activities [9].

In terms of specific behaviors, 1-2-year-old children have learned to take objects in various ways. They begin to play with toys, take objects as a "tool" to use, and be able to preliminarily use the resolution and discovery ability in the process of the game; In cognitive aspect, they will also run around, touch everywhere, accumulation of sensory experience, full of curiosity about the world; In language, they can speak two-word words and simple sentences, and like simple children's songs and stories, like to follow learning others; In social behavior, begin to appear independent, but have a certain possessiveness, do not know how to share, prefer to play alone, often self-centered.

According to the psychological characteristics and behavior of children in this age group, it can give 1-1.5-year-old children some pleasant music, provide 1.5-2 children-year-old simple graphics and 1-2 kinds of color recognition small game or courses. In terms of painting, children at this stage are more inclined to doodle, for this purpose to provide a small place, let them doodle, and provide a certain introductory video as well, set up some simple threecharacter nursery rhymes for them.

\subsubsection{Education module 2}

2-3 years old children cognitive learning module. In the behavior and movement aspect, it is mainly to develop basic movement, it can be equipped with sports equipment to exercise running, jumping, throwing, playing and other behaviors, mainly to develop the coordination and control ability of hands as well as the coordination and balance of wrists and fingers, and enhance the self-care ability of living;

In terms of cognition, they can recognize 3-5 main colors, 3 common shapes. In language, they can remember and perform two tasks, and repeat sentences with 3-5 words, like to ask, like to read books, listen to stories and read nursery rhymes, tell simple stories; in social behavior aspect, they can do basic self-care, and will show possessiveness and jealousy. 
According to their characteristics, it should set up some simple number, color, shape cognitive courses; set up audio reading; set up some stories that ease possessiveness and jealousy; set up Jigsaw Puzzles and so on.

\subsubsection{Education module 3}

3-4-year-old children's initial imitation module. In the behavior and movement aspect, they like to imitate interesting movements, expressions and tone of voice. They often paint and paste. In cognition aspect, they are able to perceive and understand the relationship between number and quantity, distinguish the size of objects, are interested in many shapes, explore things with many senses or actions, understand short nursery rhymes or stories, identify objects, and say the name of the items, read books, and like to follow the rhythm of children's songs; In social behavior aspect, they have a certain degree of self-esteem, self-confidence and self-reliance performance.

According to the characteristics of young children in this age group, it should set up some simple math course; set up storytelling course; set up some children's songs with strong rhythm; set up graffiti painting course; set up a slightly more difficult jigsaw puzzle; set up action imitation and other interesting games.

\subsubsection{Education module 4}

4-5-year-old children exploration things module. In terms of behavior and movement, they have certain balance ability, know how to do coordination, have a certain strength and endurance, hand movements are relatively flexible and coordinated; In cognition aspect, they have a preliminary ability to explore, like to contact with new things, there is further development on the perception and understanding of the relationship between number and quantity, between space and shape. They like artistic activities and actively show them; in the language aspect, they can listen carefully and understand the common language, be willing to speak and express clearly, like listening to stories and reading books, and express their mood by singing impromptu, performing familiar songs or compiling words. They have a preliminary reading comprehension ability, a desire to express in writing and preliminary skills. In social behavior aspect, they like to communicate, be able to get along well with peers, show more obvious self-esteem, self-confidence and autonomy, show concern and respect for others, and prefer to participate in some group activities.

Children aged 4-5 are curious about things. They should have lively and interesting lessons such as basic numbers, literacy, painting and nursery rhymes. They should also have some 
safety warning videos (to show which things can and cannot be imitated). It should set up some cooperative games such as friend call games, find different games, draw and guess games.

\subsubsection{Education module 5}

5-6-year-old children comprehensive learning module. This age of children are more mature in all aspects, they also have more and more ideas. In terms of behavior and movement, they are more flexible and coordinated, and their strength and endurance are improved; In cognition aspect, they have a preliminary sense of belonging, are willing to work for the collective, and are proud of the collective honor, and understand the significance of the rules; In language aspect, they like to talk about interesting topics and stories with others, are able to organize sentences to say part of children's books, listen to the stories and be able to say their own opinions, and can create stories; In social behavior aspect, they are more interested in what they like. The ability of learning and imitating is stronger, and they are curious and yearning for primary school life.

According to the characteristics of young children in this age group, it should set up math courses, music courses, literacy courses, learning videos related to understanding and handling interpersonal relationships, guide videos to distinguish wrong behavior from right behavior; set up mini comics creation games, coloring games, and select matching games and so on.

\section{MANAGEMENT PLATFORM CREATION AND OPERATION SERVICE}

\subsection{Application Technology of Platform Creation}

\subsubsection{Server interaction technology.}

The Wechat public ID port is connected to the relevant data, and users can easily access the information through the Wechat public ID platform. At the same time, users can intelligently arrange and push the target information according to their usage habits and focus areas. In this regard, the platform developers will build server interaction technology, the administrator has the right to save the data locally and link to the server, and use Wechat to subscribe to the way on demand to the front-end users, meanwhile, the server completes the check-in, query and other tasks through the related code.

\subsubsection{Mobile APP and IH5 technology.}

The establishment of user database, user behavior record analysis, the realization of data 
interchange systems, improvement of communication supply chain; IH5 development or hybrid development; Using the APPAPI interface provided by the server to access the data from the http access server, the data structure is usually JSON or XML, then the data is parsed, and then the UI framework or other frameworks or customized Ui encapsulation format is used. Set up network authentication using Cookie, Session, or Token. Because the product itself involves big data, there is also a need to introduce a third-party framework.

\subsubsection{Platform web development techniques.}

It covers computer assembly and maintenance, Flash basics, Photoshop image processing, Dreamweaver basics, dynamic web pages, CSS + XHTML, JavaScript, Flash AS, SSE-SQL, CMS applications, SEO website optimization, C\#, ASP.NET advanced programming, etc.

\subsection{Platform Port Settings and Contents}

\subsubsection{Young children port (Figure 5)}

Enlightenment Education Knowledge: With the help of quality teaching resources on the Internet and professional teachers of young children education, the platform changes the traditional general teaching mode of online enlightenment education knowledge, and combines with other preschool education expert groups to use Internet for targeted teaching, so as to help children better learn and practice knowledge, and get fair and diverse educational resources.

Children Health Care Knowledge: Invite children health care experts into the platform and regularly open children's health knowledge classroom. The children health care knowledge mainly includes various health knowledge of children in different seasons, how to protect children's eyes, how to improve their immunity, common knowledge of children's diet, common knowledge of children's sports, etc. Moreover, the online platform consultation mode is set up to facilitate users to consult with children's health care issues anytime and anywhere according to their specific situations. 


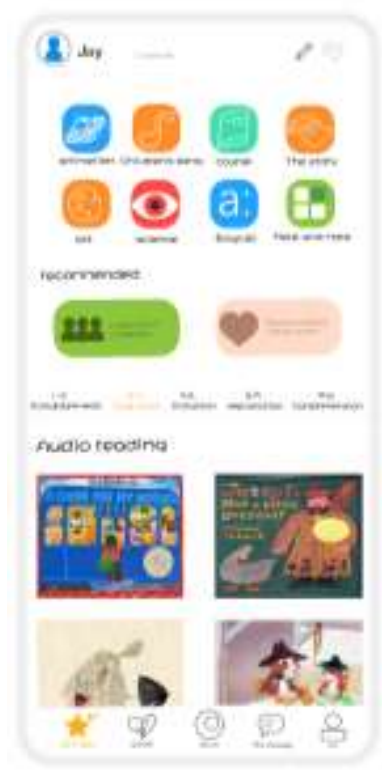

Fig 5. Young children port Interface design

Safety protection knowledge: On the one hand, provide small videos, animation and other children's favorite ways to publicize and explain safety protection knowledge. At the same time, interactive small games are set up to let children know which are dangerous objects, which are dangerous actions, how to ensure their own safety when they are at home, etc. On the other hand, the platform opens online intelligent voice consultation mode for personalized question.

Mental Health Knowledge: Firstly, invite psychology experts to enter the platform, through regular network psychological test for young children, real-time update data. Secondly, through the establishment of a cooperative relationship with the public welfare institutions of psychology to solve children's psychological problems in various ways; Thirdly, the creation of children's psychological daily analysis column, daily analysis of a child's psychological and behavioral phenomena, such as how to deal with children's grumpy temper and crying, why children like to bite their nails, and so on.

Social and legal knowledge: Release and popularize policy and legal knowledge about young children education and growth for parents and society. Invite legal education experts to settle in the platform and accept online professional consultation.

\subsubsection{Parents port (Figure 6)}

From observing as a bystander to being the main character in the design and 
implementation of teaching activities, the role of parents will change in some parts of preschool education [10]. Therefore, this platform is not only a witness to the growth of children's platform, it is also a platform to improve young children's education level and ability for parents.

Firstly, cooperate with kindergarten to build network information inquiry and communication platform. Even at home, parents can use the platform video link to pay attention to their children's learning and living conditions in kindergarten and school activities in an efficient and real-time manner. Set some humanized functions, such as drug-feeding reminder function and so on. Just click, the kindergarten will receive a reminder from the parents. It not only provides more convenience for parents, but also reduces unnecessary troubles for kindergartens.

Secondly, set up an on-line data analysis platform to collect and analyze data such as school-based data on children's learning ability, data on children's growth and development, data on children's psychological behavior in various activities, etc., so as to provide comprehensive and scientific information on children's learning and growth for parents. Simultaneously pay attention to the data security and the privacy protection.

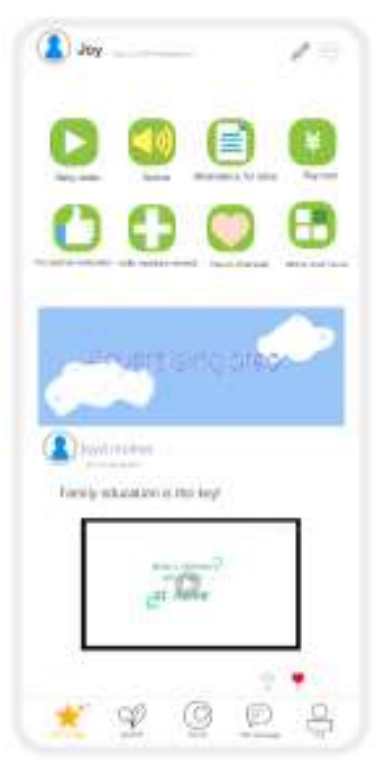

Fig 6. Parents port interface design

\subsubsection{Kindergarten port}

Establish young children's growth records. Take the kindergarten as a unit, investigate the 
young children's life, study and family education, register one by one, and establish a growth record file reflecting their progress and deficiency. Carry out the working procedures of dynamic tracking, timely filing, classified management and information sharing, and implement personalized attention and service according to the records of archives.

\subsubsection{Government port}

Free information statistics and inquiry open to the government. At the same time, under the guidance of the government, and with the help of government resources, enrich the knowledge and database of young children education. Cooperate with the government to build a platform for healthy growth of young children.

\subsubsection{Social port}

Donations from caring people of society, goods and materials and related subsidy policies, all can use the platform to connect, query and use. For the families with difficulties, the platform undertakes the third-party function. The source and use details of donation goods and materials are recorded in detail and disclosed to a certain extent. In addition, the social port of the platform also publishes the latest preschool education information to the society in real time.

\section{PLATFORM OPERATION ANALYSIS}

\subsection{SWOT Analysis}

\subsubsection{Strengths}

(1) Market demand: market demand is very strong. This platform can meet the diverse needs of different target groups with strong function and adaptability.

(2) Social context: China's social and economic development is strong, in this background, society and the media industries are increasingly concerned about "preschool education" and can make faster progress through media campaigns.

(3) State policy: With the implementation of China's two child policy, the state has paid more and more attention to the development of industries related to preschool education programs, and incentive policies have been introduced continuously.

(4) Platform advantages: The platform has multiple sections, comprehensive functions and 
effective integration of resources, at the same time achieves the information security and the classification service, the personalized service.

(5) Technology aspect: The Internet+, big data and cloud computing applications make the platform more efficient. IH5 technology enhances the convenience of using the platform with a good sense of experience and interaction.

(6) Care concept: The platform not only provides education knowledge management and service, but also establishes a multi-dimensional young children care system based on the concept of caring. That is, family monitoring platform with parents and relatives as the main body, caring platform, which is a family monitoring platform with parents and relatives as the main body, a caring platform with social organizations as the main body, and an education platform with kindergartens as the main body.

\subsubsection{Weakness}

(1) Information complexity: At present, the knowledge and information about preschool education are complex, and it is difficult to collect, sort, classify and promote on a large scale.

(2) Offline activities: There are barriers to organize offline activities because of the wide range of areas and populations involved.

(3) Integration of resources: The service targets of platform involve young children, parents, kindergartens, the government and the society, the scope is wide, and the integration of resources is difficult.

\subsubsection{Opportunities}

(1) Weak competitiveness: At present, the market in this field, which involves the service scope of this platform, is mostly the App application with single function. The platform of educational knowledge management based on IH5 interactive technology and young children psychological analysis has not been found.

(2) Policy support: The state strongly encourages the establishment of "preschool education projects" involving policies, venues, funds, taxation and other aspects.

(3) Social needs: with the improvement of economic level and educational level, parents not only pay attention to the material life of their children, but also pay more attention to their 
children's knowledge acquisition and spiritual and emotional needs.

(4) Online education: With the increasing number of Internet users in China, online education is becoming more and more popular, and people adapt to and become familiar with online education platforms.

\subsubsection{Threats}

(1) Privacy and security issues: In cloud computing, data is accessed through the network, which will lead to a series of security and privacy problems, such as database attack, data disclosure, etc.

(2) Accidental loss of data: When data interacts through the network, the loss of database connection will result in a series of consequences, such as accidental loss of data.

(3) Insufficient service capacity: large number of users, wide scope of business, large amount of information processed, need for deep customization and integration with existing systems to maintain business operations and services.

(4) Validity of information: Authenticity, accuracy, timeliness and validity of platform information need to be guaranteed, and verification and maintenance of user identity need to be guaranteed.

\subsection{Business Model}

\subsubsection{Revenue model}

\section{(1) Advertising revenue}

It mainly depends on the expenses incurred by advertising investors when they put advertisements on the platform. The principles of advertiser selection are as follows:

Units that engage in advertising business activities and have the qualification of enterprise legal person.

The enterprise has made certain contributions to the industry, public service advertising and public welfare undertakings, and has a high influence in the industry. 
The main operators and business department heads of the enterprise have bachelor degree or above and corresponding advertising business experience.

There are 3 customers who have successfully served for 2 years. In the past 2 years, provide comprehensive agency services for more than 8 brands, and at least 2 brands are successful cases.

(2) Government support

Can apply for state-related project funding, as well as access to tax breaks and other policies.

(3) Institutional donations

It can be divided into designated donation and non designated donation. The platform needs and platform public welfare content will be published online. Accept legal and effective donations from relevant institutions and enterprises, mainly including knowledge technology donation, capital donation, equipment donation, and so on.

(4) Social investment

Direct investment mainly from venture capital firms or enterprises involved in the business. The selection principles of the contractual joint venture are as follows:

Cooperation with major private kindergartens, kindergartens to provide investment, we provide education platform.

To cooperate with all the legitimate and regular enterprises of baby products, and invest in all the major supply companies, and we will advertise them.

To cooperate with other legitimate and formal education-related enterprises, and other relevant education enterprises to invest in the platform, to provide advertising or free platform applications.

\subsubsection{Return on investment}

(1) Public undertakings are also productive forces. On the one hand, they enrich the corporate culture. On the other hand, participation in public welfare undertakings is an 
important way to gain social affinity and public recognition.

(2) The enterprise may enjoy the state tax reduction and exemption policy. According to the state policy, the portion of the public welfare donation expenditure incurred by the enterprise that is within $12 \%$ of the total annual profit shall be allowed to be deducted in the calculation of the tax payable.

(3) Cost savings. Participation in public welfare undertakings, on the surface, it increases the cost of the enterprise, in fact, after enterprises devote to social public welfare undertakings, they can get much more than the amount of donations of social resources and intangible asset, to expand the social influence of enterprises. Social resources include the intangible spread of reputation and influence of enterprises, the intangible condensation of government resources and other resources. In particular, the intangible publicity of the media has brought various benefits to enterprises, which cannot be replaced by advertising.

\subsection{Business Strategy (Figure 7)}

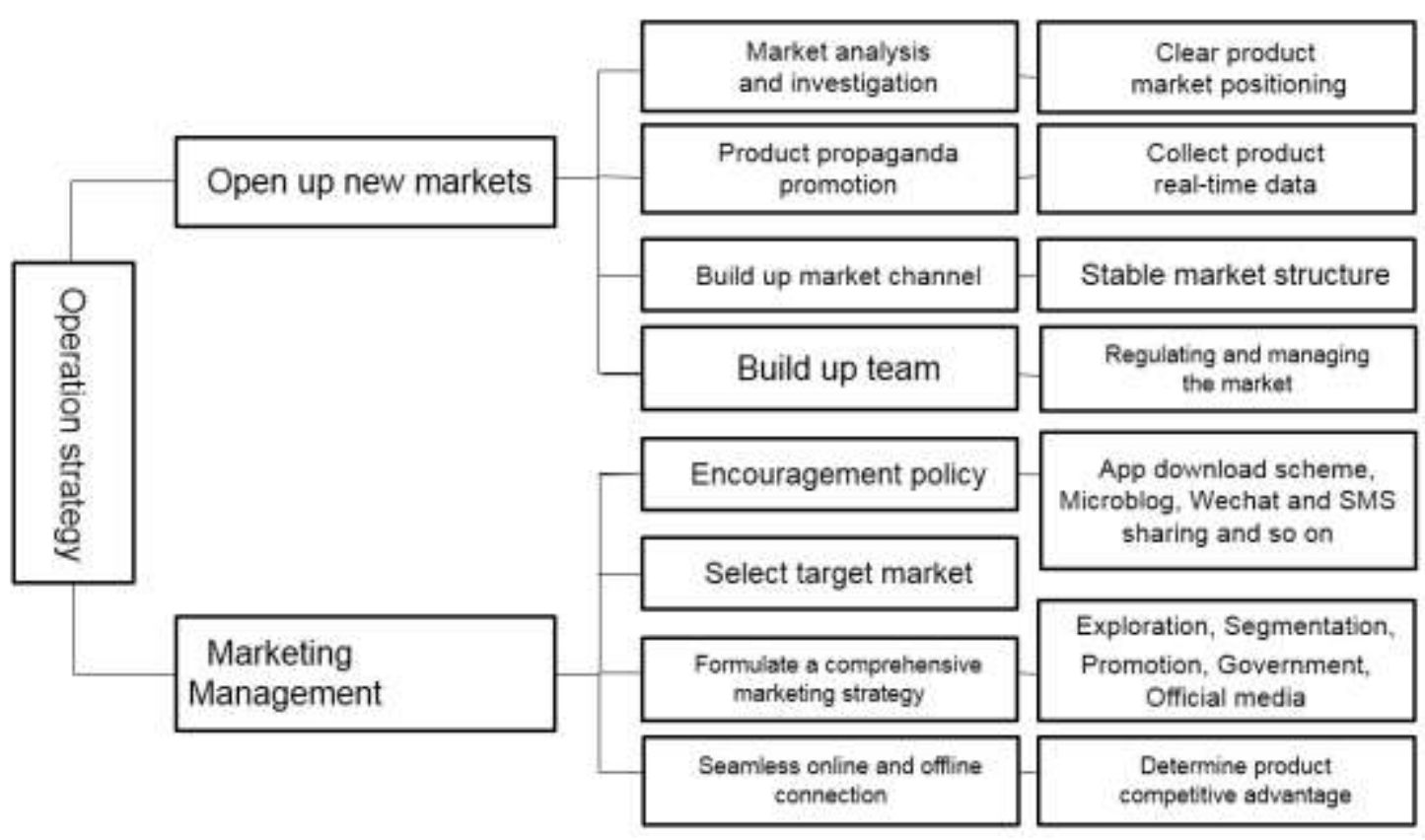

Fig 7. Operation strategy

\subsubsection{Opening up new markets}


Firstly, fully conduct market analysis and market research, make clear the market positioning of the platform, find the new market demand for the project product. Analyze and determine the position and advantages of platform products and marketing measures in the same industry, and find a breakthrough.

Secondly, the product publicity and promotion. Collect real-time data of products, launch all-round propaganda, make use of the continuous popularization of the Internet and self-media, form a communication chain, make a large number of potential customers become actual customers.

Thirdly, the establishment of market channels to form a stable market structure.

Fourthly, the establishment of a stable management team, product $\mathrm{R} \& \mathrm{D}$ team and marketing team, at the same time, real-time study and evaluation of the company's development status and prospects.

\subsubsection{Marketing management}

At first, select and confirm the market area according to the latest situation and policy. Then collect, analyze, manage, publish and update the scientific and systematic knowledge and information of young children education, formulate a comprehensive marketing strategy.

Exploration: That is to explore, through market investigation to understand what the market demand is, survey and study the market structure, consumers and competitors' behaviors, identify, evaluate and select market opportunities, to guide the information release platform.

Segmentation: The process of market segmentation. It is divided according to the factors affecting consumer demand, such as amount, distance, trust, etc. Market segmentation can greatly improve the effectiveness of platform information release and service.

Promotion: Make full use of self-media and advertising channels to make the platform bigger and stronger, so that more and more people know the comprehensive functions and scientific knowledge provided by the platform.

Government: Rely on cooperation and docking with the government, through the support of national policies, make the platform bigger and stronger.

Official media: Make Use of the power of the official news media to build up the corporate 
image and open the market for educational information release platform.

\subsubsection{User analysis}

Getting users is the first step to promotion, and then counting the number of users weekly and monthly activities. Because some of the users obtained are those who are not willing to enter directly, such as promotions, the conversion rate of users and the loss of new user need to be recorded in time. Statistics and analysis of daily retention rate, weekly retention rate and user behavior can not only provide more thoughtful services for old users, but also formulate corresponding incentive plans and schemes before new users lose.

\subsection{Financial Analysis}

\subsubsection{Internal rate of return (IRR)}

According to the cash flow statement, the internal rate of return is calculated as follows:

$\mathrm{nNPV}(\mathrm{IRR})=\Sigma(\mathrm{CI}-\mathrm{CO}) \mathrm{t}(1+\mathrm{IRR})-\mathrm{t}=0 \mathrm{IRR}=92 \% \mathrm{t}=1$

The internal rate of return is $92 \%$, much larger than the cost of capital rate of $10 \%$, mainly because of the product quality and low price, making sales profit rate is higher, and the market growth will be good in the next five years.

\subsubsection{Statement of cash flows}

Table III. Cash flow statement (Unit: Ten thousand RMB)

\begin{tabular}{|l|l|l|l|l|l|}
\hline Cash flow from project activities & $\begin{array}{l}\text { The } \\
\text { first } \\
\text { year }\end{array}$ & $\begin{array}{l}\text { The } \\
\text { second } \\
\text { year }\end{array}$ & $\begin{array}{l}\text { The } \\
\text { third } \\
\text { year }\end{array}$ & $\begin{array}{l}\text { The } \\
\text { fourth } \\
\text { year }\end{array}$ & $\begin{array}{l}\text { The } \\
\text { fifth } \\
\text { year }\end{array}$ \\
\hline Cash paid for goods and services & 58.25 & 88.35 & 158.46 & 226.45 & 305.04 \\
\hline Cash paid for operating lease & 10 & 15 & 25 & 30 & 50 \\
\hline Cash paid to employees & 50 & 70 & 90 & 120 & 180 \\
\hline Cash paid for business income tax & 0 & 0 & 0 & 60 & 120 \\
\hline $\begin{array}{l}\text { Cash paid for technical support, data } \\
\text { collection and other activities }\end{array}$ & 30.56 & 50.67 & 80.69 & 90.6 & 126.7 \\
\hline Cash paid for other activities & 118.81 & 179.02 & 294.15 & 447.05 & 681.74 \\
\hline
\end{tabular}


Article History: Received: 10 May 2021 Revised: 20 June 2021 Accepted: 18 July 2021 Publication: 16 November 2021

\begin{tabular}{|c|c|c|c|c|c|}
\hline \multicolumn{6}{|l|}{ Cash flow from investment activities } \\
\hline $\begin{array}{l}\text { Cash received from investment in fixed } \\
\text { assets }\end{array}$ & 100 & 150 & 200 & 200 & 250 \\
\hline \multicolumn{6}{|l|}{ Cash flow from financing activities } \\
\hline $\begin{array}{l}\text { Cash received from the absorption rights and } \\
\text { interests investment }\end{array}$ & 300 & 400 & 300 & 800 & 1000 \\
\hline Cash received from loan & 300 & 300 & 300 & 500 & 500 \\
\hline Cash paid for loan repayment & 0 & 0 & 0 & 0 & 300 \\
\hline Cash received for interest repayment & 20 & 30 & 40 & 60 & 50 \\
\hline Net cash flow from financing activities & 580 & 670 & 565 & 790 & 1260 \\
\hline Net increase in cash and cash equivalents & 461.19 & 495.98 & 270.85 & 342.95 & 578.26 \\
\hline
\end{tabular}

\subsection{Risk Countermeasures}

\subsubsection{Market risk and control}

(1) Product competition: After the platform brand is bigger, there is no guarantee that there will not be similar platforms, which will increase the pressure of industry competition and may increase the expansion pressure of the platform.

(2) Credit crisis: When other large-scale enterprises or most companies in the industry have credit crisis, it will lead to consumer distrust of the whole industry, which will affect the development of the whole industry.

(3) Technical Barriers: When some companies in the industry use new management methods or new technologies, the service will be faster, more convenient and cheaper. Therefore, in the short term, if the platform cannot master this technology, it will lead to the reduction of the platform's customer source.

(4) Information security: Because the product itself is information products, as the platform continues to expand and customers continue to increase, the pressure of huge information data management and security will continue to increase.

\subsubsection{Market risk solutions:}

(1) Rand advantage. Build the platform to become a leading enterprise in the industry, so that when the industry reputation crisis occurs, it will not affect the development of the platform to a large extent. 
(2) Keep abreast of the situation. Continuously research and pay attention to the development of current network technology and management knowledge, apply new technology and knowledge in the construction of this platform, and constantly improve the technology and knowledge content of the platform.

(3) Talent introduction. Strengthen team support and avoid independent project structure. Through effective team building, enhancing the support and cooperation between teams, some technical risks can also be effectively avoided.

(4) Resource integration. Strengthen and improve the communication of information to promote the integration of resources and provide better services.

(5) Refine Work Breakdown Structure (WBS). In the project planning stage, through the refinement of work package, the use of network planning and other more perfect planning means to prepare the plan, as far as possible to eliminate the root causes of technical risks, so as to achieve the purpose of reducing technical risks.

\section{CONCLUSION}

By focusing on the realistic background of the young children education and COVID-19, summarizing the psychological and behavioral characteristics of children, and combining the interactive technique of IH5, the young children education knowledge management platform is created. It not only scientifically and comprehensively locates the service targets in young children, parents, kindergartens, government and society, but also carry out platform operation service analysis, formulate operation plans and risk countermeasures. The creation and service of the system will not only provide young children education with scientific knowledge and methods, but also provide parents with a comprehensive and in-depth understanding of young children's growth, knowledge learning, industry and market development; provide the kindergarten with a platform for in-depth communication and joint efforts to implement scientific preschool education; provide data information for the government, facilitate precise support and scientific policy implementation, and provide public welfare information and young children education industry development channels for the society.

\section{ACKNOWLEDGEMENTS}

This work is supported in part by graduate education quality engineering project "Research on improving the quality and efficiency of international education in Anhui Polytechnic 
University", the talent cultivation and scientific research start-up fund project "Research on the quality standard and evaluation system of China's international education in the new stage" and Zhongjiang scholar talent project of Anhui Polytechnic University.

\section{REFERENCES}

[1] Editorial board of Encyclopedia of China (1990). China Encyclopedia. Huaxia Press, 1990.

[2] T. T. Feng (2019). Advantages and features of IH5 technology. Computer products and communication. 8: 151.

[3] L. F. Jiang (2019). Research on effective strategies of home and school cooperation based on young children mental health education. 12: 88-90.

[4] J. Zou (2017). Using multimedia technology to optimize young children teaching. Reading and writing magazine, 8: 281.

[5] X. S. Sui, Y. J. Su (2003). Verification of two component cognitive model of psychological theory. Journal of psychology, 35: 56-62.

[6] A. Lillard (1998). Ethnopsychologies: Cultural variations in theories of mind psychological Bulletin, 123: 3-32.

[7] W. M. Chen (2017). Young children psychology. Beijing Normal University Press, 2017: 155.

[8] W. M. Chen (2017). Young children psychology. Beijing Normal University Press, 2017: 161.

[9] S. Liu (2019). Research on the architectural design of kindergarten based on the characteristics of young children's psychological behavior - a case study of a kindergarten in Ziliujing District, Zigong City, Chengdu University of technology, 2019.

[10] N. Chen (2014). What children should learn -- thinking about the relationship between experience acquisition and young children's growth. Central China Normal University, 2014. 